\title{
Role of T Iymphocytes in tumor response to radiotherapy
}

\author{
Sandra Demaria ${ }^{1 *}$ and Silvia C. Formenti ${ }^{2}$ \\ 1 Department of Pathology, New York University School of Medicine and NYU Langone Medical Center, New York, NY, USA \\ ${ }^{2}$ Department of Radiation Oncology, New York University School of Medicine and NYU Langone Medical Center, New York, NY, USA
}

\section{Edited by:}

Udo S. Gaipl, University Hosptial

Erlangen, Germany

\section{Reviewed by:}

Santos Mañes, Consejo Superior de Investigaciones Científicas, Spain Elizabeth Ann Repasky, Roswell

Park Cancer Institute, USA

\section{*Correspondence:}

Sandra Demaria, Department of

Pathology, NYU Langone Medical

Center, 550 First Avenue, MSB-521,

New York, NY 10016, USA.

e-mail:sandra.demaria@nyumc.org
Over thirty years ago, Helen Stone and colleagues compared the effects of local tumor irradiation in immunocompetent and $T$ cell deficient mice, providing the first evidence that tumor response to radiotherapy is impaired in the absence of a normal T cell repertoire. In the following three decades there has been an exponential growth in understanding T cells and the complex molecular mechanisms that regulate their activation, migration to tumors and effector functions. We now also know that tumor progression is intrinsically linked to the development of multiple immunosuppressive mechanisms that allow cancer cells to escape immune control. Recent evidence about the role of $\mathrm{T}$ cells in determining the prognosis and outcome of patients at any clinical stages of cancer has been instrumental in re-directing the concept of immunosurveillance and immunoediting from the realm of preclinical models to the reality of clinical observations. Importantly, cell death induced by standard anti-cancer therapies like chemotherapy and radiation has been demonstrated to involve the immune system and, in certain specific settings, enable a specific immune response. It is, therefore, not surprising that the last few years have seen an increase in investigations exploring how to harness the ability of radiation to induce anti-tumor immune responses. We will review here the experimental evidence that anti-tumor T cells are key players in tumor control achieved by radiotherapy. The effects of radiation on the tumor that have been shown to enhance the priming and effector phases of anti-tumor immunity will be discussed. Finally, we will highlight promising combinations of immune response modifiers that enhance $T$ cell function with radiotherapy which are being tested in the clinic.

Keywords: abscopal, adjuvant, CD8 T cells, dendritic cells, immunoediting, immunotherapy, ionizing radiation, in situ vaccine

\section{INTRODUCTION}

Ionizing radiation has been employed as a cancer treatment based on its cytocidal effects, and the response to radiotherapy linked mostly to the delivery of irreparable DNA damage to tumor cells. Therefore, research to improve the efficacy of radiotherapy has been dominated by studies of the mechanisms of DNA repair, their regulation in normal and neoplastic cells, and the tumor cell factors that affect radiosensitivity, such as the phase of the cell cycle. While in vitro these parameters are determinants of the inhibition of tumor cell growth by radiation, in vivo they are essential but not sufficient to explain the response of a tumor to local radiotherapy. In fact, a report published in 1979 by Helen Stone and colleagues demonstrated that in vivo, factors extrinsic to the cancer cell are key determinants of tumor radiosensitivity (Stone et al., 1979). Instead of studying the response of human tumor xenografts that grow only in immunocompromised mice, a mouse tumor was injected in syngeneic animals. Radiosensitivity was then compared in immunocompetent and $\mathrm{T}$ cell-deficient animals. The difference was striking: tumors growing in mice that lacked $\mathrm{T}$ cells required over $60 \mathrm{~Gy}$ to achieve the same tumor control obtained with $30 \mathrm{~Gy}$ in immunocompetent mice. More than thirty years later, the key role of $\mathrm{T}$ cells as anti-tumor effectors is unquestionable in experimental mouse models as well as in humans. There is evidence from clinical trials that adoptive transfer of tumor-specific $\mathrm{T}$ cells can eliminate tumors even at advanced stages (Porter et al., 2011; Restifo et al., 2012). Significant progress has also been made in understanding how a treatment considered immunosuppressive such as radiation can induce anti-tumor $\mathrm{T}$ cells, as reviewed in this article. While the clinical evidence of systemic anti-tumor responses from local radiotherapy is rare, the uncommon observation of tumor regression outside of the radiation field was recognized by R. H. Mole and named, in 1953 as abscopal effect from the latin "ab scopus," i.e., away from the target (Mole, 1953). Based on the hypothesis that the abscopal effect is due to radiationmediated induction of anti-tumor T cells (Demaria et al., 2004), interventions that improve $\mathrm{T}$ cell activation have shown abscopal effects when combined with radiotherapy in mice and humans (Demaria et al., 2005; Formenti and Demaria, 2009; Postow et al., 2012).

To understand the role of Tlymphocytes in the tumor response to radiotherapy it is useful to review the evidence on the reciprocal influence that tumor and immune cells have on each other during tumor progression. 


\section{TUMOR-HOST IMMUNE SYSTEM: A DYNAMIC EOUILIBRIUM}

The fundamental task of the immune system is to maintain tissue homeostasis. This is an active process that requires a delicate balance between tolerance and active surveillance to detect any tissue change that is potentially dangerous. Since tissue turnover and physiological remodeling, for example in the breast post-weaning, are often associated with significant cell death, the immune system has developed sensors to distinguish it from pathogenic cell death. A key class of receptors devoted to triaging cell death are pattern recognition receptors (PRR). Expressed by innate immune cells they bind to pathogen-associated molecular pattern (PAMP) molecules derived from infectious agents and damageassociated molecular pattern (DAMP) molecules derived from cells dying a stressful death (Janeway and Medzhitov, 2002; Zeh and Lotze, 2005; Mills, 2011). The ability to resist cell death has been identified as one of the hallmarks of cancer (Hanahan and Weinberg, 2000), suggesting that, in addition to resulting in tumor growth, this property may also account for a failure of recognition of the pathogenic features of transformed cells by the immune system. However, there is plenty of evidence to the contrary and, in fact, immune recognition of cancer cells is so common that the ability to evade immune destruction has been increasingly recognized as an essential biological capability required by tumors in order to become clinically apparent (Hanahan and Weinberg, 2011). The cancer immunoediting theory provides a rationale for this apparent paradox (Dunn et al., 2002).

Neoplastic transformation is invariably associated with genomic instability and cell stress. Genomic instability leads to the generation of neoantigens-containing epitopes that can be recognized by $\mathrm{T}$ cells (Segal et al., 2008) and cell stress leads to the expression of molecules such as members of the family of NKG2D ligands that are recognized by natural killer (NK), $\gamma \delta \mathrm{T}$ cells and effector CD8 T cells (Diefenbach et al., 2000; Hayakawa et al., 2002). Local disruption of the stroma and of normal tissue architecture generates danger signals in the form of DAMPs, including degraded extracellular matrix components (e.g., heparin sulfate, hyaluronan) (Lotze et al., 2007) that attract innate immune cells. Recognition of the stressed neoplastic cells by NK or other innate immune cells results in production of interferon (IFN)- $\gamma$, a cytokine shown to play a key role in immunosurveillance against tumors (Street et al., 2001; Dunn et al., 2006). Killing of the neoplastic cells by NK cells or macrophages activated by IFN- $\gamma$ to produce cytocidal reactive oxygen and nitrogen species, eventually leads to crosspresentation by dendritic cells (DC) of antigens from the dying tumor cells to $\mathrm{T}$ cells and activation of the adaptive immune system. Tumor-specific $\mathrm{T}$ cells may be able to completely destroy the incipient tumor, thus functioning as an extrinsic tumor suppressor mechanism that reduces the incidence of spontaneous and carcinogen-induced tumors. This is supported by unequivocal evidence in experimental models and indirect evidence in humans with various immunodeficiencies [reviewed in Dunn et al. (2004) and Vesely et al. (2011)]. However, if complete elimination of genomically unstable cells is not achieved, the immunological pressure results in selection of clones of neoplastic cells that have acquired, via mutations or epigenetic changes, resistance to immune rejection, i.e., are "edited" by the immune system to become poorly immunogenic. This transition from elimination to escape can occur directly, or sometimes can occur after a long period of equilibrium, during which the immune response is able to prevent or limit the progression of cancer. The concept of equilibrium, initially formulated to explain clinical observations of occult tumors and tumor dormancy (Myron Kauffman et al., 2002; MacKie et al., 2003), has been confirmed in experimental models: depletion of $\mathrm{T}$ cells leads to growth of occult tumors that are more immunogenic, indicating that much of the immunoediting occurs during the equilibrium phase (Koebel et al., 2007). Importantly, recent evidence demonstrates that CD8 T cells play a key role in "editing out" strongly immunogenic tumor antigens (DuPage et al., 2012; Matsushita et al., 2012).

The same property that allows tumors to escape immune control may become their Achille's Heel. Tumors with high levels of genomic instability due to microsatellite instability (MSI) are prone to generate novel tumor antigens. They are often highly infiltrated by $\mathrm{T}$ cells and their carriers often enjoy better clinical outcomes, an association suggestive of better immune control (Buckowitz et al., 2005; Chiaravalli et al., 2006). Importantly, the association between infiltration by CD8 T cells and improved prognosis is not exclusive to tumors with MSI (Zhang et al., 2003; Galon et al., 2006; Pagès et al., 2010). This observation suggests that the degree and type of immune response matters at every stage of tumor progression, including metastatic disease. For example, the ability of immunotherapeutic strategies to improve survival of patients with metastatic melanoma (Hodi et al., 2010) indicates that even in advanced stages, when tumors have escaped immune control, it is possible to enhance anti-tumor $\mathrm{T}$ cell reactivity to revert to a phase of equilibrium, even in the presence of more extensive tumor burden.

Tumor's escape from immune control is a complex process, which does not only occur via antigenic loss. To avoid immune rejection tumors exploit multiple pathways that physiologically maintain immune tolerance to "self" and protect healthy tissues from immune destruction during acute inflammatory reactions. The recruitment of suppressive, tolerogenic and regulatory innate and adaptive immune cells, the secretion of immune suppressive cytokines and the induction of dysfunctional differentiation of $\mathrm{T}$ cells can be seen in most, if not all tumors [reviewed in Demaria (2012)]. In addition, cancer cells downregulate major histocompatibility complex (MHC) class I molecules that are required for recognition by CD8 $\mathrm{T}$ cells (Chang and Ferrone, 2007), and upregulate immunosuppressive receptors that preclude their destruction by T cells (Dong et al., 2002). The tumor vasculature also presents multiple barriers to $\mathrm{T}$ cell infiltration, through an abnormal architecture and a relative paucity of endothelial adhesion molecules (Chen et al., 2003). Overall, the tumor microenvironment evolves into a protective hub for the neoplastic cells, that actively prevents tumor rejection. In this context, ionizing radiation acts as a modifier of the microenvironment with the potential to switch the immunosuppressive hub into an immunogenic one (Demaria and Formenti, 2007). 


\section{ROLE OF THE IMMUNE SYSTEM IN RESPONSE TO LOCAL RADIOTHERAPY}

Although radiation has been known to have pro-inflammatory and immunomodulatory effects for a long time (McBride et al., 2004), it is only recently that some of these changes have been elucidated at a molecular level. These studies have provided evidence for the counterintuitive concept that local radiotherapy, rather than suppressing anti-tumor immunity, can promote it. A series of important findings in relation to the main barriers to immune rejection that are affected by radiation have emerged.

As mentioned above, the correct assessment of cell death by innate immune cells as "dangerous" or "non-dangerous" dictates which downstream pathways are triggered to either activate adaptive immunity or maintain tolerance. The traditional dichotomy of cell death as apoptotic and non-inflammatory versus necrotic and inflammatory has been challenged by the demonstration that apoptotic death can be associated with release of pro-inflammatory and danger signals (Galluzzi et al., 2007). The stressful death of cancer cells induced by some types of chemotherapy and by ionizing radiation can be quite immunogenic and promote the cross-presentation of tumor-derived antigens by DC to T cells, leading to development of anti-tumor responses (Ma et al., 2010; Zitvogel et al., 2010). Among the three molecular signals identified as critical for the successful induction of immunogenic cell death, both, translocation of calreticulin (CRT) to the surface of the dying cell and release of high-mobility group protein B1 (HMGB1), which binds to the PRR Toll-Like Receptor (TLR) 4, are induced by ionizing radiation (Apetoh et al., 2007; Obeid et al., 2007). The third signal, active release of ATP by cells committed to apoptotic death, which is required to activate the NLRP3 inflammasome (Ghiringhelli et al., 2009) is still awaiting confirmation in irradiated cells. Given recent evidence that autophagy is required for ATP release (Michaud et al., 2011), and that ionizing radiation promotes autophagy (Rieber and Rieber, 2008; Rodriguez-Rocha et al., 2011), this third signal is likely to be generated by radiotherapy when autophagy precedes cell death. Overall, experimental evidence supports the contention that radiation can induce a tumor cell death that is perceived by the immune system as dangerous and, therefore, generates an in situ cancer vaccine.

Once activated, $\mathrm{T}$ cells have to be able to home to and infiltrate the tumor. Radiation has been shown to promote this process in multiple ways. For instance, radiation-induced remodeling of the abnormal tumor vessels, resulted in efficient tumor infiltration by adoptively transferred anti-tumor T cells in a spontaneous mouse tumor model (Ganss et al., 2002). In a murine experimental model of melanoma, up-regulation of vascular cell adhesion molecule (VCAM)-1 induced by radiation increased infiltration by $\mathrm{T}$ cells, in a process requiring IFN- $\gamma$ production (Lugade et al., 2005, 2008). Our group demonstrated in a poorly immunogenic mouse carcinoma that radiation-induced up-regulation of the chemokine CXCL16 was required for the efficient recruitment to the tumor of CXCR6 ${ }^{+}$effector CD8 T cells, resulting in optimal tumor inhibition (Matsumura et al., 2008). Other important effects of radiation include the up-regulation of MHC class I molecules, adhesion molecules, NKG2D ligands, and Fas/CD95, enhancing the ability of effector $\mathrm{T}$ cells to bind to and kill the cancer cells (Hareyama et al., 1991; Gaugler et al., 1997; Chakraborty et al., 2003, 2004; Garnett et al., 2004; Gasser et al., 2005; Kim et al., 2006; Newcomb et al., 2006; Reits et al., 2006). Thus, radiation is a significant modifier of tumor microenvironment with specific effects that facilitate tumor rejection (Figure 1).

Despite the multiple pro-immunogenic effects, radiation by itself is usually insufficient to generate strong and lasting $\mathrm{T}$ cell responses that in addition to contributing to eradicate the irradiated tumor can control the growth of established metastases. Multiple immunosuppressive pathways make it very difficult to overcome these barriers by radiotherapy alone, in the absence of additional interventions. However, addition of antibodies to block a negative regulator of $\mathrm{T}$ cell activation, the checkpoint receptor cytotoxic T-lymphocyte-associated antigen 4 (CTLA4 ), induced therapeutically significant anti-tumor immunity to a poorly immunogenic carcinoma treated with local radiotherapy, while each treatment by itself was not effective (Demaria et al., 2005). In addition, radiation induces effects that can dampen the immune response, like the activation of transforming growth factor (TGF) $\beta$ (Jobling et al., 2006), and a relative increase in regulatory T cells (Kachikwu et al., 2011). Altogether, the pre-existing balance between tolerogenic and effector antitumor mediators, and the degree to which radiation can induce activation without stimulating suppression, converge to determine the outcome in terms of local and systemic tumor control. Intriguingly, there is at least some evidence that the type of the radiation regimen employed may have a role in determining whether a favorable pro-immunogenic response is elicited (Dewan et al., 2009).

\section{HARNESSING THE PRO-IMMUNOGENIC EFFECTS OF RADIATION IN CANCER TREATMENT: A NEW PARADIGM}

Progress in understanding the function and dysfunction of the immune system in cancer has identified specific targets for intervention, based on the dominant immunosuppressive mechanism in a given tumor type and/or patient (Zitvogel et al., 2011). The growing evidence that local radiotherapy can generate an in situ vaccine supports its use in concert with personalized immunotherapy, since the killed tumor cells provide the entire antigenic diversity of a patient's own tumor.

Since DC function is often suboptimal in tumors, studies have tested strategies to increase DC numbers and function by administering DC growth factors in combination with radiotherapy. Experimental work in two syngeneic mouse models, a lung and a mammary carcinoma, employed Flt-3 ligand as growth factor to expand DC, and demonstrated the induction of a T cell-mediated response that reduced tumor growth outside the field of radiation (Chakravarty et al., 1999; Demaria et al., 2004). Based on this data, we conducted a clinical trial that used s.c. GM-CSF to increase the percentage of DC and their maturation and facilitate cross-presentation of newly released antigens, after cell death at the site of radiotherapy. We selected patients with at least 3 metastatic sites from solid tumors. With a standard radiation fractionation of 3.5 Gy X10 fractions delivered to one tumor site we were able to measure an out-of field (abscopal) response in 30\% of the patients with metastatic solid tumors accrued to the trial 


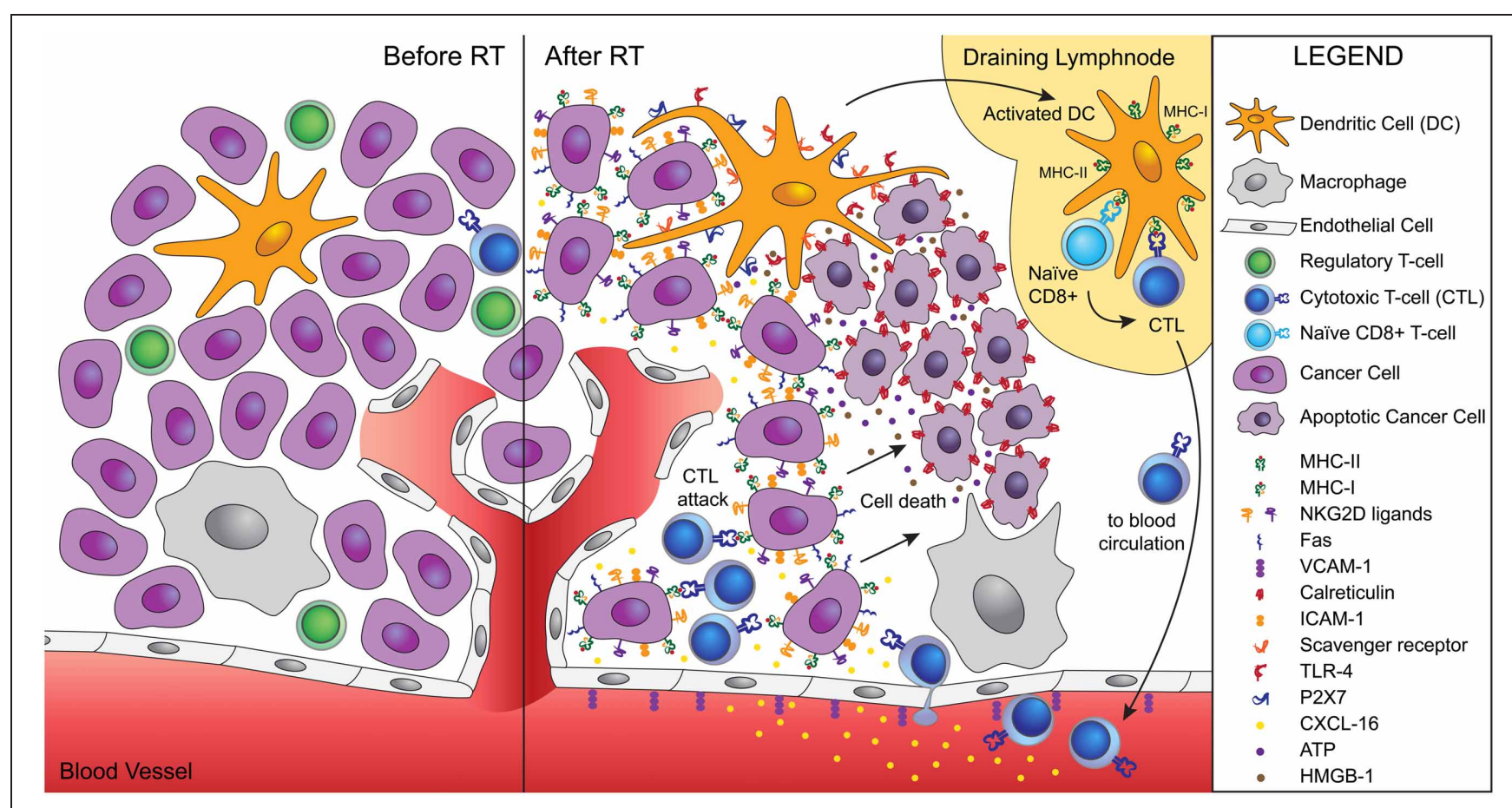

FIGURE 1 | lonizing radiation acts as a modifier of the tumor microenvironment converting the tumor into an in situ vaccine.

Radiation induces an immunogenic cell death of tumor cells characterized by calreticulin translocation to the surface of dying cells, and release of HMGB-1 and ATP. Calreticulin allows uptake of dying cells by dendritic cells via scavenger receptor(s). HMGB-1 binds to TLR4 and promotes the cross-presentation of tumor antigens, while ATP binds to P2X7 and triggers the activation of the inflammasome. Activated dendritic cells migrate to the draining lymph node, where they activate naïve $T$ cells specific for tumor antigens. Activated CD8 T cells acquire effector functions and traffic to the tumor guided by radiation-induced chemokines. Tumor infiltration by CTLs is facilitated by radiation-induced upregulation of VCAM-1 on the vascular endothelium. Once in the tumor, CTLs interact efficiently with tumor cells expressing increased levels of MHC-I, ICAM-1, NKG2D ligands, and Fas that promote the formation of stable immunological synapses between targets and effectors and facilitate the killing of tumor cells by CTLs. Tumor cells killed by CTLs become a source of antigens for cross-presentation, thus fueling the process.
(Formenti and Demaria, 2009). In murine models, exogenously prepared DC injected in the tumor following radiation induced anti-tumor immune responses (Nikitina and Gabrilovich, 2001; Teitz-Tennenbaum et al., 2003; Kim et al., 2004). These effects were translated in the majority of patients with hepatoma and high risk sarcoma treated in two early clinical trials (Chi et al., 2005; Finkelstein et al., 2012). In preclinical models molecular mimics of the danger signals associated with pathogens, like olygodeoxynucleotides containing CpG motifs that bind to TLR9, when injected intratumorally enhanced DC activation and ability to cross-present tumor antigens released by radiation (Milas et al., 2004; Mason et al., 2005). A similar combination of local radiotherapy and $\mathrm{CpG}$ administration was tested in 15 patients with low-grade B-cell lymphoma, showing abscopal responses, associated with development of tumor-specific T cells (Brody et al., 2010). Taken together, the data support the ability of radiation to generate an in situ vaccine: the efficacy of this approach is dependent on DC fitness and can be enhanced by interventions directed at improving DC.

A complementary strategy is based on targeting checkpoint coinhibitory receptors or co-stimulatory receptors expressed by $\mathrm{T}$ cells with blocking or agonistic antibodies, respectively, to achieve stronger and more sustained responses of anti-tumor $\mathrm{T}$ cells. Our group tested the hypothesis that inhibiting a key checkpoint receptor, CTLA-4, in combination with radiotherapy would induce therapeutically effective anti-tumor responses. While CTLA-4 is a dominant inhibitory receptor for T cells, as demonstrated by the development of uncontrolled $\mathrm{T}$ cell proliferation in mice deficient in CTLA-4 (Chambers et al., 1997), CTLA-4 blockade as monotherapy failed to induce regression of poorly immunogenic tumors, requiring its use in combination with vaccination (Peggs et al., 2008). Therefore, we hypothesized that radiotherapy would synergize with anti-CTLA-4, due to its ability to generate an in situ vaccine. This hypothesis was confirmed in mice models of poorly immunogenic carcinomas (Demaria et al., 2005; Dewan et al., 2009). The therapeutic efficacy of the anti-tumor $\mathrm{T}$ cells activated by treatment was enhanced by other effects of radiation such as an improved tumor infiltration by effector T cells, confirming it's beneficial effects at both the priming and effector phase of anti-tumor responses (Matsumura et al., 2008). A recent case report suggests that the success of the combination of local radiotherapy and anti-CTLA-4 can be translated in melanoma patients (Postow et al., 2012), with multiple clinical trials being conducted to confirm these results.

Targeting of other co-stimulatory or co-inhibitory receptors expressed by T cells, CD137 and programmed death (PD)-1, respectively, has also shown some success in combination with radiation in mice models (Newcomb et al., 2010; Verbrugge et al., 2012), supporting more studies to develop these strategies for clinical use. 
A number of other studies exploited the pro-immunogenic effects of local radiotherapy that promote the effector phase of tumor rejection, by combining radiation with either vaccination or adoptive immune therapy (AIT). Increased expression of MHC class I antigens by irradiated glioma cells was implicated in the synergy of peripheral vaccination with whole brain radiation (Newcomb et al., 2006). In a mouse carcinoma, radiationinduced Fas expression was shown to synergize with T cell AIT and with vaccination, by facilitating tumor cell killing by $\mathrm{T}$ cells (Chakraborty et al., 2003, 2004). Interestingly, following the combination of vaccine and local radiation there was an induction of $\mathrm{T}$ cells specific for tumor antigens not present in the vaccine, a phenomenon known as antigen cascade or antigenic spread. Similarly, antigen cascade was also observed in prostate cancer patients treated with standard definitive radiotherapy and vaccination (Gulley et al., 2005).

\section{CONCLUSIONS}

Immune response modifiers (IRM) have been defined by the National Cancer Institute Translational Research Working Group

\section{REFERENCES}

Apetoh, L., Ghiringhelli, F., Tesniere, A., Obeid, M., Ortiz, C., Criollo, A., Mignot, G., Maiuri, M. C., Ullrich, E., Saulnier, P., Yang, H., Amigorena, S., Ryffel, B., Barrat, F. J., Saftig, P., Levi, F., Lidereau, R., Nogues, C., Mira, J. P., Chompret, A., Joulin, V., Clavel-Chapelon, F., Bourhis, J., André, F., Delaloge, S., Tursz, T., Kroemer, G., and Zitvogel, L. (2007). Toll-like receptor 4-dependent contribution of the immune system to anticancer chemotherapy and radiotherapy. Nat. Med. 13, 1050-1059.

Brody, J. D., Ai, W. Z., Czerwinski, D. K., Torchia, J. A., Levy, M., Advani, R. H., Kim, Y. H., Hoppe, R. T., Knox, S. J., Shin, L. K., Wapnir, I., Tibshirani, R. J., and Levy, R. (2010). In situ vaccination with a TLR9 agonist induces systemic lymphoma regression: a phase I/II study. J. Clin. Oncol. 28, 4324-4332.

Buckowitz, A., Knaebel, H. P., Benner, A., Bläker, H., Gebert, J., Kienle, P., von Knebel Doeberitz, M., and Kloor, M. (2005). Microsatellite instability in colorectal cancer is associated with local lymphocyte infiltration and low frequency of distant metastases. Br. J. Cancer 92, 1746-1753.

Chakraborty, M., Abrams, S. I., Camphausen, K., Liu, K., Scott, T., Coleman, C. N., and Hodge, J. W. (2003). Irradiation of tumor cells up-regulates Fas and enhances CTL lytic activity and CTL adoptive immunotherapy. J. Immunol. 170, 6338-6347.

Chakraborty, M., Abrams, S. I., Coleman, C. N., Camphausen, K., Schlom, J., and Hodge, J. W. (2004). External beam radiation of tumors alters phenotype of tumor cells to render them susceptible to vaccine-mediated T-cell killing. Cancer Res. 64, 4328-4337.

Chakravarty, P. K., Alfieri, A., Thomas, E. K., Beri, V., Tanaka, K. E., Vikram, B., and Guha, C. (1999). Flt3-Ligand administration after radiation therapy prolongs survival in a murine model of metastatic lung cancer. Cancer Res. 59, 6028-6032.

Chambers, C. A., Sullivan, T. J., and Allison, J. P. (1997). Lymphoproliferation in CTLA4-deficient mice is mediated by costimulation-dependent activation of $\mathrm{CD} 4+\mathrm{T}$ cells. Immunity 7 , 885-895.

Chang, C. C., and Ferrone, S. (2007). Immune selective pressure and HLA class I antigen defects in malignant lesions. Cancer Immunol. Immunother. 56, 227-236.

Cheever, M. A., Schlom, J., Weiner, L. M., Lyerly, H. K., Disis, M. L., Greenwood, A., Grad, O., Nelson, W. G., and Group, T. R. W. (2008). Translational Research Working Group developmental pathway for immune response modifiers. Clin. Cancer Res. 14, 5692-5699.

Chen, Q., Wang, W. C., and Evans, S. S. (2003). Tumor microvasculature as a barrier to antitumor immunity.

as "immunotherapy agents that mimic, augment, or require participation of the host immune system for optimal effectiveness" (Cheever et al., 2008). Although host T cells contribution to the optimal tumor response to radiation was demonstrated over three decades ago (Stone et al., 1979), it is only in the last decade that the underlying mechanisms begun to be understood. Increasing number of publications testing new combinations of radiation and immunotherapy testify to the growing interest toward a new role of radiation as an "immunological adjuvant". Most exciting is the emerging evidence that radiation may indeed function as an IRM in patients, suggesting that it may be time to consider a paradigm shift in the use of radiotherapy.

\section{ACKNOWLEDGMENTS}

The authors would like to thank Dr. Lorenzo Agoni for designing the figure in this manuscript. The authors are supported by grants from NIH, R01 CA113851 (Sandra Demaria) and R01 CA161891 (Silvia C. Formenti), The Chemotherapy Foundation (Sandra Demaria), USA Department of Defense Breast Cancer Research Program BC100481 (Silvia C. Formenti and Sandra Demaria).

Cancer Immunol. Immunother. 52, 670-679.

Chi, K. H., Liu, S. J., Li, C. P., Kuo, H. P., Wang, Y. S., Chao, Y., and Hsieh, S. L. (2005). Combination of conformal radiotherapy and intratumoral injection of adoptive dendritic cell immunotherapy in refractory hepatoma J. Immunother. 28 , 129-135.

Chiaravalli, A. M., Feltri, M., Bertolini, V., Bagnoli, E., Furlan, D., Cerutti, R., Novario, R., and Capella, C. (2006). Intratumour $T$ cells, their activation status and survival in gastric carcinomas characterised for microsatellite instability and Epstein-Barr virus infection. Virchows Arch. 448, 344-353.

Demaria, S. (2012) "Immune escape: immunosuppressive networks," in Cancer Immunotherapy, eds G. C. Prendergast and E. M. Jaffee (New York, NY: Elsevier Inc.).

Demaria, S., and Formenti, S. C. (2007). Sensors of ionizing radiation effects on the immunological microenvironment of cancer. Int. J. Radiat. Biol. 83, 819-825.

Demaria, S., Kawashima, N., Yang, A. M., Devitt, M.-L., Babb, J. S., Allison, J. P., and Formenti, S. C. (2005). Immune-mediated inhibition of metastases following treatment with local radiation and CTLA- 4 blockade in a mouse model of breast cancer. Clin. Cancer Res. $11,728-734$.

Demaria, S., Ng, B., Devitt, M.-L., Babb, J. S., Kawashima, N., Liebes, L., and Formenti, S. C. (2004).
Ionizing radiation inhibition of distant untreated tumors (abscopal effect) is immune mediated. Int. J. Radiat. Oncol. Biol. Phys. 58, 862-870.

Dewan, M. Z., Galloway, A. E., Kawashima, N., Dewyngaert, J. K., Babb, J. S., Formenti, S. C., and Demaria, S. (2009). Fractionated but not single dose radiotherapy induces an immune-mediated abscopal effect when combined with anti-CTLA-4 antibody. Clin. Cancer Res. 15, 5379-5388.

Diefenbach, A., Jamieson, A. M., Liu, S. D., Shastri, N., and Raulet, D. H. (2000). Ligands for the murine NKG2D receptor: expression by tumor cells and activation of NK cells and macrophages Nat. Immunol. 1, 119-126.

Dong, H., Strome, S. E., Salomao, D. R., Tamura, H., Hirano, F., Flies, D. B., Roche, P. C., Lu, J., Zhu, G., Tamada, K., Lennon, V. A., Celis, E., and Chen, L. (2002). Tumor-associated B7-H1 promotes T-cell apoptosis: a potential mechanism of immune evasion. Nat. Med. 8, 793-800.

DuPage, M., Mazumdar, C., Schmidt, L. M., Cheung, A. F., and Jacks, T. (2012). Expression of tumourspecific antigens underlies cancer immunoediting Nature 482, 405-409.

Dunn, G. P., Bruce, A. T., Ikeda, H., Old, L. J., and Schreiber, R. D. (2002). Cancer immunoediting: from immunosurveillance to tumor escape. Nat. Immunol. 3, 991-998. 
Dunn, G. P., Koebel, C. M., and Schreiber, R. D. (2006). Interferons, immunity and cancer immunoediting. Nat. Rev. Immunol. 6, 836-848.

Dunn, G. P., Old, L. J., and Schreiber, R. D. (2004). The three Es of cancer immunoediting. Annu. Rev. Immunol. 22, 329-360.

Finkelstein, S. E., Iclozan, C., Bui, M. M., Cotter, M. J., Ramakrishnan, R., Ahmed, J., Noyes, D. R., Cheong, D., Gonzalez, R. J., Heysek, R. V., Berman, C., Lenox, B. C., Janssen, W., Zager, J. S., Sondak, V. K., Letson, G. D., Antonia, S. J., and Gabrilovich, D. I. (2012). Combination of external beam radiotherapy (EBRT) with intratumoral injection of dendritic cells as neo-adjuvant treatment of high-risk soft tissue sarcoma patients Int. J. Radiat. Oncol. Biol. Phys. 82, 924-932.

Formenti, S. C., and Demaria, S. (2009). Systemic effects of local radiotherapy. Lancet Oncol. 10, 718-726.

Galluzzi, L., Maiuri, M. C., Vitale, I., Zischka, H., Castedo, M., Zitvogel, L., and Kroemer, G. (2007). Cell death modalities: classification and pathophysiological implications. Cell Death Differ. 14, 1237-1243.

Galon, J., Costes, A., Sanchez-Cabo, F., Kirilovsky, A., Mlecnik, B., LagorcePages, C., Tosolini, M., Camus, M., Berger, A., Wind, P., Zinzindohoue, F., Bruneval, P., Cugnenc, P. H., Trajanoski, Z., Fridman, W. H., and Pages, F. (2006). Type, density, and location of immune cells within human colorectal tumors predict clinical outcome. Science 313, 1960-1964.

Ganss, R., Ryschich, E., Klar, E., Arnold, B., and Hammerling, G. J. (2002). Combination of T-cell therapy and trigger of inflammation induces remodeling of the vasculature and tumor eradication Cancer Res. 62, 1462-1470.

Garnett, C. T., Palena, C., Chakarborty, M., Tsang, K. Y., Schlom, J., and Hodge, J. W. (2004). Sublethal irradiation of human tumor cells modulates phenotype resulting in enhanced killing by cytotoxic T lymphocytes. Cancer Res. 64, 7985-7994.

Gasser, S., Orsulic, S., Brown, E. J., and Raulet, D. H. (2005). The DNA damage pathway regulates innate immune system ligands of the NKG2D receptor. Nature 436, 1186-1190.

Gaugler, M. H., Squiban, C., van der Meeren, A., Bertho, J. M., Vandamme, M., and Mouthon,
M. A. (1997). Late and persistent up-regulation of intercellular adhesion molecule-1 (ICAM-1) expression by ionizing radiation in human endothelial cells in vitro. Int J. Radiat. Biol. 72, 201-209.

Ghiringhelli, F., Apetoh, L., Tesniere, A., Aymeric, L., Ma, Y., Ortiz, C., Vermaelen, K., Panaretakis, T., Mignot, G., Ullrich, E., Perfettini, J. L., Schlemmer, F., Tasdemir, E., Uhl, M., Génin, P., Civas, A., Ryffel, B., Kanellopoulos, J., Tschopp, J., André, F., Lidereau, R., McLaughlin, N. M., Haynes, N. M., Smyth, M. J., Kroemer, G., and Zitvogel, L. (2009). Activation of the NLRP3 inflammasome in dendritic cells induces IL-1beta-dependent adaptive immunity against tumors. Nat. Med. 15, 1170-1178.

Gulley, J. L., Arlen, P. M., Bastian, N., Morin, N., Marte, J., Beetham, P., Tsang, K.-Y., Yokokawa, J., Hodge, J. W., Menard, C., Camphausen, K., Coleman, C. N., Sullivan, F., Steinberg, S. M., Schlom, J., and Dahut, P. (2005). Combining a recombinant cancer vaccine with standard definitive radiotherapy in patients with localized prostate cancer. Clin. Cancer Res. 11, 3353-3362.

Hanahan, D., and Weinberg, R. A. (2000). The hallmarks of cancer Cell 100, 57-70.

Hanahan, D., and Weinberg, R. A. (2011). Hallmarks of cancer: the next generation. Cell 144, 646-674.

Hareyama, M., Imai, K., Kubo, K., Takahashi, H., Koshiba, H., Hinoda, Y., Shidou, M., Oouchi, A., Yachi, A., and Morita, K. (1991). Effect of radiation on the expression of carcinoembryonic antigen of human gastric adenocarcinoma cells. Cancer 67, 2269-2274.

Hayakawa, Y., Kelly, J. M., Westwood, J. A., Darcy, P. K., Diefenbach, A. Raulet, D., and Smyth, M. J. (2002). Cutting edge: tumor rejection mediated by NKG2D receptor-ligand interaction is dependent upon perforin J. Immunol. 169, 5377-5381.

Hodi, F. S., O'Day, S. J., McDermott, D. F., Weber, R. W., Sosman, J. A., Haanen, J. B., Gonzalez, R., Robert, C., Schadendorf, D., Hassel, J. C., Akerley, W., van den Eertwegh, A. J., Lutzky, J., Lorigan, P., Vaubel, J. M., Linette, G. P., Hogg, D., Ottensmeier, C. H., Lebbé, C. Peschel, C., Quirt, I., Clark, J. I., Wolchok, J. D., Weber, J. S., Tian, J., Yellin, M. J., Nichol, G. M., Hoos, A., and Urba, W. J. (2010). Improved survival with ipilimumab in patients with metastatic melanoma. N. Engl. J. Med. 363, 711-723.
Janeway, C. A. J., and Medzhitov, R (2002). Innate immune recognition. Annu. Rev. Immunol. 20, 197-216.

Jobling, M. F., Mott, J. D., Finnegan, M. T., Jurukovski, V., Erickson, A. C., Walian, P. J., Taylor, S. E., Ledbetter, S., Lawrence, C. M. Rifkin, D. B., and Barcellos-Hoff, M H. (2006). Isoform-specific activation of latent transforming growth factor beta (LTGF-beta) by reactive oxygen species. Radiat. Res. 166 839-848.

Kachikwu, E. L., Iwamoto, K. S., Liao, Y. P., DeMarco, J. J., Agazaryan, N., Economou, J. S., McBride, W. H., and Schaue, D. (2011). Radiation enhances regulatory $\mathrm{T}$ cell representation. Int. J. Radiat. Oncol. Biol. Phys. 81, 1128-1135.

Kim, J. Y., Son, Y. O., Park, S. W. Bae, J. H., Chung, J. S., Kim, H. H., Chung, B. S., Kim, S. H., and Kang, C. D. (2006). Increase of NKG2D ligands and sensitivity to NK cell-mediated cytotoxicity of tumor cells by heat shock and ionizing radiation. Exp. Mol. Med. 38 474-484.

Kim, K. W., Kim, S. H., Shin, J. G., Kim, G. S., Son, Y. O., Park, S. W., Kwon, B. H., Kim, D. W., Lee, C. H., Sol, M. Y., Jeong, M. H., Chung, B. S., and Kang, C. D. (2004). Direct injection of immature dendritic cells into irradiated tumor induces efficient antitumor immunity. Int. J. Cancer 109, 685-690.

Koebel, C. M., Vermi, W., Swann, J. B. Zerafa, N., Rodig, S. J., Old, L. J., Smyth, M. J., and Schreiber, R. D. (2007). Adaptive immunity maintains occult cancer in an equilibrium state. Nature 450, 903-907.

Lotze, M. T., Zeh, H. J., Rubartelli, A. Sparvero, L. J., Amoscato, A. A., Washburn, N. R., Devera, M. E. Liang, X., Tör, M., and Billiar, T. (2007). The grateful dead: damageassociated molecular pattern molecules and reduction/oxidation regulate immunity. Immunol. Rev. 220, 60-81.

Lugade, A. A., Moran, J. P., Gerber, S. A., Rose, R. C., Frelinger, J. G., and Lord, E. M. (2005). Local radiation therapy of B16 melanoma tumors increases the generation of tumor antigen-specific effector cells that traffic to the tumor. J. Immunol. 174 7516-7523.

Lugade, A. A., Sorensen, E. W., Gerber S. A., Moran, J. P., Frelinger, J. G., and Lord, E. M. (2008) Radiation-induced IFN-gamma production within the tumor microenvironment influences antitumor immunity J. Immunol. 180, 3132-3139.
Ma, Y., Kepp, O., Ghiringhelli, F., Apetoh, L., Aymeric, L., Locher, C., Tesniere, A., Martins, I., Ly, A., Haynes, N. M., Smyth, M. J., Kroemer, G., and Zitvogel, L. (2010). Chemotherapy and radiotherapy: cryptic anticancer vaccines. Semin. Immunol. 22 113-124.

MacKie, R. M., Reid, R., and Junor, B. (2003). Fatal melanoma transferred in a donated kidney 16 years after melanoma surgery N. Engl. J. Med. 348, 567-568.

Mason, K. A., Ariga, H., Neal, R., Valdecanas, D., Hunter, N., Krieg, A. M., Whisnant, J. K., and Milas, L. (2005). Targeting toll-like receptor 9 with CpG oligodeoxynucleotides enhances tumor response to fractionated radiotherapy. Clin. Cancer Res. 11, 361-369.

Matsumura, S., Wang, B., Kawashima, N., Braunstein, S., Badura, M., Cameron, T. O., Babb, J. S. Schneider, R. J., Formenti, S. C. Dustin, M. L., and Demaria, S. (2008). Radiation-induced CXCL16 release by breast cancer cells attracts effector T cells. J. Immunol. 181, 3099-3107.

Matsushita, H., Vesely, M. D., Koboldt, D. C., Rickert, C. G., Uppaluri, R., Magrini, V. J., Arthur, C. D., White, J. M., Chen, Y. S., Shea, L. K., Hundal, J., Wendl, M. C., Demeter, R., Wylie, T., Allison, J. P., Smyth, M. J., Old, L. J., Mardis, E. R., and Schreiber, R. D. (2012) Cancer exome analysis reveals a $\mathrm{T}$ cell-dependent mechanism of cancer immunoediting. Nature 482, 400-404.

McBride, W. H., Chiang, C.-S., Olson, J. L., Wang, C.-C., Hong, J.-H., Pajonk, F., Dougherty, G. J., Iwamoto, K. S., Pervan, M., and Liao, Y.-P. (2004). A sense of danger from radiation. Radiat. Res. 162, $1-19$

Michaud, M., Martins, I., Sukkurwala, A. Q., Adjemian, S., Ma, Y., Pellegatti, P., Shen, S., Kepp, O., Scoazec, M., Mignot, G., RelloVarona, S., Tailler, M., Menger, L., Vacchelli, E., Galluzzi, L., Ghiringhelli, F., Di Virgilio, F., Zitvogel, L., and Kroemer, G. (2011). Autophagy-dependent anticancer immune responses induced by chemotherapeutic agents in mice. Science 334, 1573-1577.

Milas, L., Mason, K. A., Ariga, H., Hunter, N., Neal, R., Valdecanas, D., Krieg, A. M., and Whisnant, J. K. (2004). CpG oligodeoxynucleotide enhances tumor response to radiation. Cancer Res. 64, 5074-5077. 
Mills, K. H. (2011). TLR-dependent $\mathrm{T}$ cell activation in autoimmunity. Nat. Rev. Immunol. 11, 807-822.

Mole, R. J. (1953). Whole body irradiation-radiology or medicine? Br. J. Radiol. 26, 234-241.

Myron Kauffman, H., McBride, M. A., Cherikh, W. S., Spain, P. C., Marks, W. H., and Roza, A. M. (2002). Transplant tumor registry: donor related malignancies. Transplantation 74, 358-362.

Newcomb, E. W., Demaria, S., Lukyanov, Y., Shao, Y., Schnee, T., Kawashima, N., Lan, L., Dewyngaert, J. K., Zagzag, D., McBride, W. H., and Formenti, S. C. (2006). The combination of ionizing radiation and peripheral vaccination produces long-term survival of mice bearing established invasive GL261 gliomas. Clin. Cancer Res. 12, 4730-4737.

Newcomb, E. W., Lukyanov, Y., Kawashima, N., Alonso-Basanta, M., Wang, S.-C., Liu, M., JureKunkel, M., Zagzag, D., Demaria, S., and Formenti, S. C. (2010). Radiotherapy enhances antitumor effect of anti-CD137 therapy in a mouse Glioma model. Radiat. Res. 173, 426-432.

Nikitina, E. Y., and Gabrilovich, D. I. (2001). Combination of gamma-irradiation and dendritic cell administration induces a potent antitumor response in tumor-bearing mice: approach to treatment of advanced stage cancer. Int. J. Cancer 94, 825-833.

Obeid, M., Panaretakis, T., Joza, N., Tufi, R., Tesniere, A., van Endert, P., Zitvogel, L., and Kroemer, G. (2007). Calreticulin exposure is required for the immunogenicity of gamma-irradiation and UVC light-induced apoptosis Cell Death Differ. 14, 1848-1850.
Pagès, F., Galon, J., Dieu-Nosjean, M. C., Tartour, E., Sautès-Fridman, C., and Fridman, W. H. (2010). Immune infiltration in human tumors: a prognostic factor that should not be ignored. Oncogene 29, 1093-1102.

Peggs, K. S., Quezada, S. A., and Allison, J. P. (2008). Cell intrinsic mechanisms of T-cell inhibition and application to cancer therapy. Immunol. Rev. 224, 141-165.

Porter, D. L., Levine, B. L., Kalos, M., Bagg, A., and June, C. H (2011). Chimeric antigen receptormodified $\mathrm{T}$ cells in chronic lymphoid leukemia. N. Engl. J. Med. 365, 725-733.

Postow, M. A., Callahan, M. K., Barker, C. A., Yamada, Y., Yuan, J., Kitano, S., Mu, Z., Rasalan, T., Adamow, M., Ritter, E., Sedrak, C., Jungbluth, A. A., Chua, R., Yang, A. S., Roman, R. A., Rosner, S., Benson, B., Allison, J. P., Lesokhin, A. M., Gnjatic, S., and Wolchok, J. D. (2012). Immunologic correlates of the abscopal effect in a patient with melanoma. N. Engl. J. Med. 366, 925-931.

Reits, E. A., Hodge, J. W., Herberts, C. A., Groothuis, T. A., Chakraborty, M., Wansley, E. K., Camphausen, K., Luiten, R. M., de Ru, A. H., Neijssen, J., Griekspoor, A., Mesman, E., Verreck, F. A., Spits, H., Schlom, J., van Veelen, P., and Neefjes, J. J. (2006). Radiation modulates the peptide repertoire, enhances MHC class I expression, and induces successful antitumor immunotherapy J. Exp. Med. 203, 1259-1271.

Restifo, N. P., Dudley, M. E., and Rosenberg, S. A. (2012). Adoptive immunotherapy for cancer: harnessing the T cell response. Nat. Rev. Immunol. 12, 269-281.

Rieber, M., and Rieber, M. S. (2008). Sensitization to radiation-induced DNA damage accelerates loss of bcl-2 and increases apoptosis and autophagy. Cancer Biol. Ther. 7, 1561-1566.

Rodriguez-Rocha, H., Garcia-Garcia, A., Panayiotidis, M. I., and Franco, R. (2011). DNA damage and autophagy. Mutat. Res. 711, 158-166.

Segal, N. H., Parsons, D. W., Peggs, K. S., Velculescu, V., Kinzler, K. W., Vogelstein, B., and Allison, J. P. (2008). Epitope landscape in breast and colorectal cancer. Cancer Res. 68, 889-892.

Stone, H. B., Peters, L. J., and Milas, L. (1979). Effect of host immune capability on radiocurability and subsequent transplantability of a murine fibrosarcoma. J. Natl. Cancer Inst. 63, 1229-1235.

Street, S. E., Cretney, E., and Smyth, M. J. (2001). Perforin and interferongamma activities independently control tumor initiation, growth, and metastasis. Blood 97, 192-197.

Teitz-Tennenbaum, S., Li, Q. Rynkiewicz, S., Ito, F., Davis, M. A., McGinn, C. J., and Chang, A. E. (2003). Radiotherapy potentiates the therapeutic efficacy of intratumoral dendritic cell administration. Cancer Res. 63, 8466-8475.

Verbrugge, I., Hagekyriakou, J., Sharp, L. L., Galli, M., West, A C., McLaughlin, N. M., Duret, H., Yagita, H., Johnstone, R. W., Smyth, M. J., and Haynes, N. M. (2012). Radiotherapy increases the permissiveness of established mammary tumors to rejection by immunomodulatory antibodies. Cancer Res. 72, 3163-3174.

Vesely, M. D., Kershaw, M. H. Schreiber, R. D., and Smyth, M. J. (2011). Natural innate and adaptive immunity to cancer. Annu. Rev. Immunol. 29, 235-271.

Zeh, H. Jr., and Lotze, M. T. (2005). Addicted to death: invasive cancer and the immune response to unscheduled cell death. J. Immunother. 28, 1-9.

Zhang, L., Conejo-Garcia, J. R., Katsaros, D., Gimotty, P. A., Massobrio, M., Regnani, G., Makrigiannakis, A., Gray, H., Schlienger, K., Liebman, M. N., Rubin, S. C., and Coukos, G. (2003). Intratumoral T cells, recurrence, and survival in epithelial ovarian cancer. N. Engl. J. Med. 348, 203-213.

Zitvogel, L., Kepp, O., and Kroemer, G. (2010). Decoding cell death signals in inflammation and immunity. Cell 140, 798-804.

Zitvogel, L., Kepp, O., and Kroemer, G. (2011). Immune parameters affecting the efficacy of chemotherapeutic regimens. Nat. Rev. Clin. Oncol. 8, 151-160.

Conflict of Interest Statement: The authors declare that the research was conducted in the absence of any commercial or financial relationships that could be construed as a potential conflict of interest.

Received: 01 June 2012; accepted: 23 July 2012; published online: 24 August 2012. Citation: Demaria $S$ and Formenti SC (2012) Role of T lymphocytes in tumor response to radiotherapy. Front. Oncol. 2:95. doi: 10.3389/fonc.2012.00095

This article was submitted to Frontiers in Molecular and Cellular Oncology, a specialty of Frontiers in Oncology. Copyright (C) 2012 Demaria and Formenti. This is an open-access article distributed under the terms of the Creative Commons Attribution License, which permits use, distribution and reproduction in other forums, provided the original authors and source are credited and subject to any copyright notices concerning any third-party graphics etc. 